\title{
An Educational Intervention to Prevent Irrational Prescribing By Primary Care Physicians: Results from Turkey from the OTC-SOCIOMED Project Second Phase
}

Yeşim Uncu ${ }^{\mathrm{a}}$

Züleyha Alper

\author{
Emre İşçí
}

Okay Başak ${ }^{e}$

\section{Ayşegül Yildirım ${ }^{\complement}$}

\begin{abstract}
Objective: The misuse of over-the-counter (OTC) medications is a serious issue in primary healthcare, leading to the need for better education of general physicians on appropriate prescribing behavior. This study discusses the findings from the OTC-SOCIOMED project (Assessing the Over-the-Counter Medications in Primary Care and Translating the Theory of Planned Behavior into Interventions) in Turkey. Methods: During November 2011, the implementation of intervention was done in Bursa, which was selected as the study region in Turkey. The participants were 28 family physicians in Turkey who were assigned to two study groups; a three-step training intervention - a 1-day intensive course on rational drug prescription, 4 weeks of reminder messages, and face-to-face interviews-was provided for the intervention group. Four different data collection tools were used before and after the intervention: a training assessment questionnaire, a complementary questionnaire on OTC medicines, the theory of planned behavior questionnaire, and a patient medication form. Results: Participants were satisfied with the quality of the training, the delivery of the topics, and the subsequent reminder messages. There was a significant difference in only one item ("The decision to prescribe belongs completely to me"), which evaluated behavior control in the intervention group after training. The lack of time most often explained why physicians could not inform patients about OTC medicines. Conclusion: Physicians were aware of their own need for training in rational prescribing, and this training model was quite acceptable to them. However, the short study duration was an obstacle for observing attitude changes among the doctors.
\end{abstract}

Keywords: Irrational Prescription $\bullet$ Over-the-counter $\bullet$ Continuing Education

a Corresponding author

Yeşim Uncu, M.D., Department of Family Medicine, Faculty of Medicine, Uludag University, Bursa, Turkey

Research areas: Family medicine; Healthy life behavior; family counseling

Email: yesimuncu@gmail.com

b Züleyha Alper, M.D., Department of Family Medicine, Faculty of Medicine, Uludag University, Bursa, Turkey Email: zalper@uludag.edu.tr

c Ayşegül Yıldırım, M.D., Ph.D., Department of Health Management, Faculty of Health Sciences, Trakya University, Edirne, Turkey

Email: draysegulyildirim@gmail.com

d Emre İşçi, Ph.D., Department of Health Management, Faculty of Health Sciences, Marmara University, Istanbul, Turkey Email: emreisci@yahoo.com

e Okay Başak, M.D., Department of Family Medicine, Faculty of Medicine, Adnan Menderes University, Aydın, Turkey Email: okaybasak@yahoo.com 
The misuse of over-the-counter (OTC) medicines and irrational prescribing are serious problems in primary healthcare settings. The World Health Organization (WHO) reported that nearly half of all prescription medicines are unnecessary or misused and that half of all patients use prescribed medicines inappropriately (WHO, 2012). Polypharmacy, insufficient self-medication, and prescription noncompliant with clinical guidelines are important factors in irrational prescribing.

The WHO has suggested that all countries strive toward the rational use of medicines through healthcare policies, information, and education (WHO, 2012). It has been demonstrated that the most effective approach for promoting rational medicine use in the primary healthcare system is the simultaneous supervision of both healthcare providers and users (WHO, 2012). Previous studies have shown that educational interventions lead to changes in the prescribing attitudes of primary healthcare physicians (De Vires, Henning, Hogerzeil, \& Fresle, 1994).

Irrational prescribing remains one of the most important problems in primary healthcare in Turkey (Tsiantou et al., 2013). A transformation of the healthcare system in Turkey was launched in 2005, and primary healthcare services began to be provided by general practitioners (GPs) known as family physicians. Every family physician serves a population and is paid by the state per capita. If people are not satisfied with their family physicians, they can change them. These circumstances lead to demanding patients and submissive doctors. Further, many medicines, including prescription drugs, can be bought over the counter, and it is customary in Turkey to use such medicines according to third-party recommendations (e.g., friend, relative). Additionally, all vitamins, dietary supplements, and herbal products are included in OTC medicines.

Multiple underlying factors, such as economic, educational, and sociocultural factors, lead to the irrational use of medicines. Inadequate physician training is cited as one of the major factors governing this problem in Turkey (Akici et al., 2004).

This study aimed to investigate the impact of intervention training for family physicians in reducing OTC prescribing and it also sought to assess the effectiveness, practicality, and acceptance of the intervention in a local setting in Turkey. 


\section{Subjects and Methods}

\section{Design}

This feasibility study was designed as a cross-sectional study, in light of the data obtained in the previous work packages of the OTC-SOCIOMED project. The OTC-SOCIOMED: Assessing the Over-the-Counter Medications in Primary Care and Translating the Theory of Planned Behavior into Interventions (EU $7^{\text {th }}$ Framework Project, no. 223654-06/05/08) was developed as a European Union project and was financed by the Seventh Framework Program (FP7). The aim of this project was to investigate the factors that influence prescribing OTC medicines and the irrational use of medicines in primary healthcare settings in five Southern European countries. GPs and other primary healthcare workers are the first to make contact with patients; thus, they represent an appropriate population for such interventions (Hrisos et al., 2009). In the first phase, the observational findings of the project were used in planning the intervention training. In the second phase, implementation of the study and evaluation of the intervention were conducted. One to two primary healthcare areas in each of the five countries (Cyprus, Greece, Malta, France, and Turkey) were selected for the pilot intervention. During November 2011, the implementation of intervention was done in Bursa, which was selected as the study region in Turkey.

The theoretical framework of the study consisted of the theory of planned behavior (TPB), which is a behavioral change model in general practice. According to the TPB, a person's intention for any behavior is affected by perceptions, social pressures from the environment, and personal perceptions of behavioral control, and the person's intention is the most important predictor of his or her behavior (Ajzen, 2011). This reasoning lies behind our hypothesis that planned training of physicians may change their intentions and prescription behavior.

The details of the study, which was based on this theory, were presented in another article and will not be repeated here (Lionis et al., 2014).

Ethical approval was obtained in each country (TR no: 2010-6/1) from the local authorities and the National Bioethics Committees within the OTCSOCIOMED Project framework. The study was conducted in accordance 
with the Helsinki Declaration and was approved by the Ethics Committee of University of Uludag and the approval form was provided during submission.

\section{Study Setting}

Bursa, one of the three regions of the previous execution of the OTCSOCIOMED project, was selected as the area for the current study. Bursa is the fourth largest city in Turkey, and the population comprises primarily immigrants from across the country. Thus, this heterogeneous population could be accepted as representative of Turkey. Physicians were invited to participate in the study by an email in which the study was briefly explained. A total of 29 volunteers from the first applicant volunteers were randomly divided into a control group of 14 and an intervention group of 15 . However, one volunteer withdrew from the study group for other reasons. The control and study groups were selected from different family healthcare centers to prevent the spread of information between groups. Informed consent was obtained from all GPs prior to their participation in the study.

\section{Implementation of Intervention}

The three-step intervention used in this study was defined as an appropriate behavioral change model for primary healthcare based on the TPB (Conner $\&$ Norman, 1995). In the first step, participants were given a 1-day intensive course on rational prescribing; how to prevent patients from misusing OTC medicines; and developing cooperation strategies using various training techniques, including recreational activities, case discussions, lectures, and small-group workshops. There were five educators, of whom three were academicians in pharmacology and two were from family medicine. One of the pharmacologists specialized in OTC medicines.

The topic titles can be summarized as rational drug use principles, polypharmacy in the elderly, OTC medicines and interactions with other medicines, and food and herbal products. The second step consisted of message reminders comprising emails and posters that were created by the study group while brainstorming on various topics, such as rational prescribing, unnecessary 
OTC drug use, and patient safety. In the third step, trainers visited participants at their workplaces. During these visits, training reminders were provided via face-to-face interviews during the physician's daily practice. This stage lasted for 4 weeks.

\section{Instruments}

Four different instruments were used before and after the intervention. All of the instruments were reviewed and culturally tested prior to their implementation in the study settings.

Training Assessment Questionnaire: Participants were given a questionnaire to evaluate the training program and to gain insight into their expectations. Responses were scored on a 7 -point Likert scale $(1=$ strongly disagree; $7=$ strongly agree), and the content of the program and the educators were assessed.

Complementary Questionnaire on OTC Medicines: In this questionnaire, physicians' attitudes toward OTC drugs and their recommendations in daily practice were studied with open- and closed-ended questions and real patient scenarios. Both groups completed the questionnaire before and after the intervention.

TPB Questionnaire: This questionnaire was established based on findings that were obtained from a previously implemented FP5 project (the ResearchBased Education and Quality Improvement Project). The questionnaire includes four questions that measure attitudes, three that measure social habits, three that measure planned behavior control, and four that measure intentions. The questions were rated on a 7 -point Likert scale. Participants were given a code at the beginning of the intervention to evaluate the questionnaires before and after the intervention.

Patient Medication Form: Physicians' records for five patients in both the intervention and control groups were examined. These patients were aged above 60 years and were given prescriptions for their chronic illnesses within 2 days before and after the training intervention. 


\section{Statistical Evaluation}

In this study, the appropriateness of the distribution sample size was observed for suitability features, and nonparametric tests were used. The Mann-Whitney $\mathrm{U}$ test and Wilcoxon's test were used for the central distribution tables and prevalence measures. In all analyses, $p<.05$ indicated statistical significance. SPSS 19.0 software (SPSS, Inc., Chicago, IL, USA) was used for data entry and analysis.

\section{Results}

The OTC-SOCIOMED project publication consisted of results from five countries that participated in the study (Lionis et al., 2014). For interpreting the results, only fully completed questionnaires were included, and 23 cases from Turkey were included in those data. However, this article is intended for local interpretation of the data; thus, all participants were included in the analyses.

There were no significant differences between the intervention and control groups in terms of mean age (intervention group: $41.85 \pm 2.44$ years; control group: $43.64 \pm 3.31$ years), gender distribution, professional experience, or specialty.

All participants who worked with other physicians at family healthcare centers had public status, and the mean population per physician was 3600 people (range: 2500-6000).

\section{Assessment of Training}

Participants were generally satisfied with the quality of training, the delivery of topics from the educators, and the subsequent reminder messages (Table 1). However, they did not expect that their attitudes toward prescribing would change. Answers to the open-ended questions about their views on the training can be summarized as follows: 
- "Training should be given to all healthcare providers and should be repeated."

- "The Ministry of Health should support this training."

. "Training should be more comprehensive."

- "The duration of training is inadequate."

- "Questions on the questionnaire should be more comprehensive."

- "Reminders and posters were very informative; reminders should continue."

- "More focus should be given to current problems in prescribing."

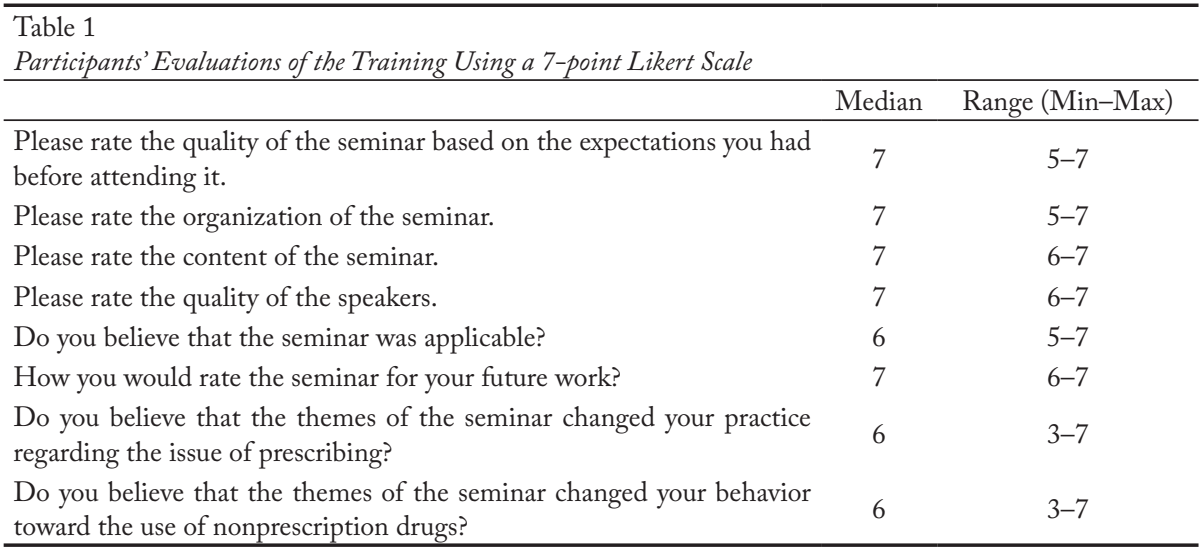

\section{Complementary Questionnaire}

When asked whether they found it important to include information about OTC use in their consultations, nearly all of the physicians said "yes" (92.3\% pre-intervention; $100 \%$ post-intervention) in certain consultations or in specific populations. They stated that the most common reasons for not talking with patients about OTC medicines were insufficient time, insufficient knowledge, and not believing in their ability to change patients' attitudes (Table 2).

When we evaluated the physicians' prescribing behaviors in the first two given scenarios, most of their attitudes were against prescribing; however, they would 
do so if another doctor had already initiated the medication after informing the patient of the potential risks. Nearly all stated that they would make time for patients who requested information (Table 2).

\begin{tabular}{|c|c|c|c|c|}
\hline \multicolumn{5}{|l|}{$\begin{array}{l}\text { Table } 2 \\
\text { Responses to the Complementary Questionnaire }\end{array}$} \\
\hline & \multicolumn{2}{|c|}{ Intervention Group } & \multicolumn{2}{|c|}{ Control Group } \\
\hline & $\begin{array}{l}\mathrm{BT}^{*} \\
n(\%)\end{array}$ & $\begin{array}{l}\mathrm{AT}^{* *} \\
n(\%)\end{array}$ & $\begin{array}{l}\mathrm{BT}^{*} \\
n(\%)\end{array}$ & $\begin{array}{l}\mathrm{AT}^{* *} \\
n(\%)\end{array}$ \\
\hline \multicolumn{5}{|c|}{ Do you think it is important to include information about OTC use in your consultations? How often? } \\
\hline In each consultation & $7(50.0)$ & $8(57.0)$ & $3(21.4)$ & $3(21.4)$ \\
\hline In certain consultations & $4(28.5)$ & $4(28.5)$ & $4(28.5)$ & $4(28.5)$ \\
\hline Only in specific populations & $3(21.4)$ & $2(14.2)$ & $3(21.4)$ & $7(50.0)$ \\
\hline \multicolumn{5}{|l|}{ Why do you think patients use OTC drugs? } \\
\hline Easily available & $8(57.0)$ & $7(50.0)$ & $7(50.0)$ & $7(50.0)$ \\
\hline They are safe because they are so easily available & $8(57.0)$ & $10(71.4)$ & $3(21.4)$ & $5(35.7)$ \\
\hline $\begin{array}{l}\text { Pharmacists can make proper suggestions based on } \\
\text { symptoms }\end{array}$ & $9(64.2)$ & $12(85.7)$ & $12(85.7)$ & $9(64.2)$ \\
\hline $\begin{array}{l}\text { The patients save time and money compared with a doctor's } \\
\text { visit. }\end{array}$ & $3(21.4)$ & $3(21.4)$ & $5(35.7)$ & $6(42.8)$ \\
\hline \multicolumn{5}{|c|}{ Could GPs have an essential role in consulting and changing patients' attitudes toward OTC use? } \\
\hline Yes & $12(85.7)$ & $12(85.7)$ & $14(100)$ & $11(78.5)$ \\
\hline No & $1(7.1)$ & $1(7.1)$ & $0(0.0)$ & $0(0.0)$ \\
\hline \multicolumn{5}{|c|}{$\begin{array}{l}\text { You have a patient who often uses OTC drugs, exchanges medicine within the family and with neighbors and } \\
\text { friends, or consults the pharmacist and purchases drugs without a prescription? What do you do in this situation? }\end{array}$} \\
\hline $\begin{array}{l}\text { Inform the patient immediately of the dangers that can } \\
\text { occur from this behavior }\end{array}$ & $13(92.8)$ & $12(85.7)$ & $12(85.7)$ & $8(57.0)$ \\
\hline Inform a family member of the patient's behavior & $0(0.0)$ & $0(0.0)$ & $0(0.0)$ & $1(7.1)$ \\
\hline $\begin{array}{l}\text { Continue to follow the patient's health and intervene when } \\
\text { necessary }\end{array}$ & $1(7.1)$ & $4(28.5)$ & $2(14.2)$ & $0(0.0)$ \\
\hline \multicolumn{5}{|l|}{ Why do you think it is important to control OTC medicines? } \\
\hline It is important for patient safety & $14(100)$ & $14(100)$ & $14(100)$ & $14(100)$ \\
\hline It is important to reduce government spending & $9(64.2)$ & $5(35.7)$ & $5(35.7)$ & $2(14.2)$ \\
\hline I do not think it is important because there are no risks from use & $1(7.1)$ & $0(0.0)$ & $0(0.0)$ & $1(7.1)$ \\
\hline I do not think it is important & $0(0.0)$ & $0(0.0)$ & $0(0.0)$ & $1(7.1)$ \\
\hline \multicolumn{5}{|c|}{$\begin{array}{l}\text { Why do you think that doctors do not investigate the consumption of OTC medicines among their patients and do } \\
\text { not provide adequate information? }\end{array}$} \\
\hline It is not considered important & $1(7.1)$ & $8(57.0)$ & $2(14.2)$ & $2(14.2)$ \\
\hline There is insufficient knowledge & $3(21.4)$ & $4(28.5)$ & $1(7.1)$ & $3(21.4)$ \\
\hline The patients will not change their attitudes either way & $3(21.4)$ & $1(7.1)$ & $4(28.5)$ & $3(21.4)$ \\
\hline Not enough time & $7(50.0)$ & $6(42.8)$ & $8(57.0)$ & $11(78.5)$ \\
\hline \multicolumn{5}{|l|}{ With which people can you collaborate to control OTC abuse? } \\
\hline Other physicians & $5(35.7)$ & $3(21.4)$ & $5(35.7)$ & $5(35.7)$ \\
\hline Other healthcare providers, i.e., nurses & $1(7.1)$ & $3(21.4)$ & $1(7.1)$ & $4(28.5)$ \\
\hline Pharmacists & $4(28.5)$ & $4(28.5)$ & $2(14.2)$ & $5(35.7)$ \\
\hline Patients & $3(21.4)$ & $3(21.4)$ & $2(14.2)$ & $4(28.5)$ \\
\hline
\end{tabular}


Table 2

Responses to the Complementary Questionnaire

\begin{tabular}{|c|c|c|c|c|}
\hline & \multicolumn{2}{|c|}{ Intervention Group } & \multicolumn{2}{|c|}{ Control Group } \\
\hline & $\begin{array}{c}\mathrm{BT}^{*} \\
n(\%)\end{array}$ & $\begin{array}{l}\mathrm{AT}^{* *} \\
n(\%)\end{array}$ & $\begin{array}{l}\mathrm{BT}^{*} \\
n(\%)\end{array}$ & $\begin{array}{l}\mathrm{AT}^{* *} \\
n(\%)\end{array}$ \\
\hline All of the above & $6(42.8)$ & $9(64.2)$ & $8(57.0)$ & $8(57.0)$ \\
\hline \multicolumn{5}{|c|}{$\begin{array}{l}\text { A patient visiting your healthcare center asks you to prescribe him/her medicines he/she has already purchased from } \\
\text { the pharmacy without a prescription. What do you do in this situation? }\end{array}$} \\
\hline You prescribe it & $0(0.0)$ & $0(0.0)$ & $1(7.1)$ & $0(0.0)$ \\
\hline You prescribe it after explaining the potential risks & $1(7.1)$ & $1(7.1)$ & $1(7.1)$ & $1(7.1)$ \\
\hline $\begin{array}{l}\text { You prescribe it for the last time, after explaining the } \\
\text { potential risks }\end{array}$ & $4(28.5)$ & $5(35.7)$ & $9(64.2)$ & $8(57.0)$ \\
\hline You do not prescribe it & $9(64.2)$ & $8(57.0)$ & $3(21.4)$ & $5(35.7)$ \\
\hline
\end{tabular}

When, instead of the patient, a third person (relative, friend, etc.) visits your healthcare center asking you to prescribe medicine that was already purchased from the pharmacy without prescription, what do you do in this situation?

You prescribe it

$1(7.1) \quad 0(0.0) \quad 0(0.0) \quad 0(0.0)$

You prescribe it after explaining the potential risks related with the consumption of this medicine to the third person

$0(0.0) \quad 2(14.2) \quad 1(7.1) \quad 1(7.1)$

You ask for the patient who wants the prescription to come

$4(28.5) \quad 3(21.4) \quad 6(42.8) \quad 3(21.4)$

You do not prescribe it

$9(64.2) \quad 9(64.2) \quad 7(50.0) \quad 10(71.4)$

A patient suffering from a chronic disease is visiting you at the healthcare center. Do you spend time discussing the medicines you prescribed?

$\begin{array}{lllll}\text { Yes, always } & 8(57.0) & 11(78.5) & 8(57.0) & 7(50.0)\end{array}$

No, it is not necessary because the medication is familiar to $\quad \begin{array}{llll}0(0.0) & 0(0.0) & 0(0.0) & 1(7.1)\end{array}$

the patient

$0(0.0)-0(0.0)+0(0.0)-1(7.1)$

Only when something changes in the patients' health condition

$3(21.4) \quad 3(21.4) \quad 6(42.8) \quad 6(42.8)$

No, because of limited time

$3(21.4) \quad 0(0.0) \quad 0(0.0) \quad 0(0.0)$

A patient visiting you at the healthcare center for a regular examination is asking you to prescribe him/her medicine that another doctor has suggested. What do you do in this situation?

\begin{tabular}{lcccc} 
You prescribe it without any comments & $4(28.5)$ & $1(7.1)$ & $2(14.2)$ & $3(21.4)$ \\
$\begin{array}{l}\text { You prescribe it after informing him/her of the potential } \\
\text { risks of drug interactions }\end{array}$ & $8(57.0)$ & $9(64.2)$ & $10(71.4)$ & $7(50.0)$ \\
$\begin{array}{l}\text { You prescribe it if you contact the doctor who suggested the } \\
\text { medication }\end{array}$ & $0(0.0)$ & $1(7.1)$ & $1(7.1)$ & $1(7.1)$ \\
You do not prescribe it & $2(14.2)$ & $3(21.4)$ & $1(7.1)$ & $3(21.4)$ \\
\hline
\end{tabular}

BT*: beginning of the study; $\mathrm{AT}^{* *}$ : end of the study 


\section{TPB Questionnaire}

In the assessments before and after the training, there were no differences in physician attitudes, subjective norms, or intentions. The only difference noted was on one item (question 14: "The decision to prescribe/recommend medication is entirely up to me"), which evaluated behavior control in the intervention group after training $(p<.05)$ (Table 3). There was no significant difference in the control group for answers to the same question before and after the training $(p>.05)$.

Table 3

Physicians'Attitudes, Subjective Norms, Planned Behavior Control, and Intention Scores from the TPB Questionnaire before and After Training

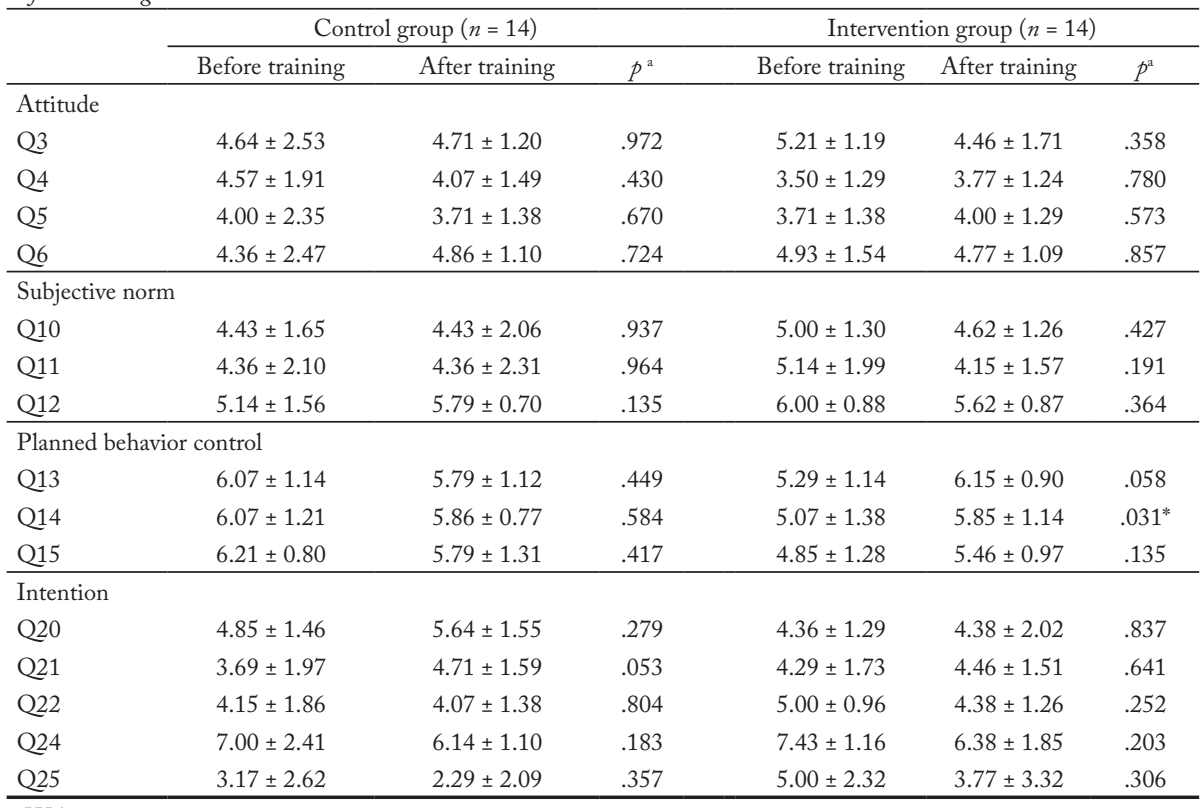

${ }^{a}$ Wilcoxon test

Data are presented as the mean \pm standard deviation ${ }^{*} p<.05$.

\section{Medical Records}

The physicians' medical records were evaluated through their prescriptions. In the intervention group, 242 drug prescriptions were written for 207 diagnoses before 
training and 173 prescriptions were written for 163 diagnoses after training. In the control group, the physicians prescribed 279 prescriptions for 226 diagnoses before training and 214 prescriptions for 194 diagnoses after training. A marginal decrease in the number of medicines prescribed after the intervention was noticeable, but the difference was not statistically significant $(p>.05)$.

\section{Discussion}

In the primary healthcare system, both patients' expectations and physicians' attitudes are responsible for irrational prescribing and the misuse of OTC medicines (Akici et al., 2004; Otoom \& Sequeira, 2006). Inappropriate usage of medicine leads to increased drug costs attributable to the increased hospitalizations caused by drug-drug interactions and side effects that put patients' health at risk; these factors create a two-way burden on healthcare expenditures.

Multiple studies have been conducted to address irrational prescribing and the effects of physician education on prescription attitudes. Continuing education in the primary healthcare system demonstrated up to $75 \%$ effectiveness (Arnold \& Straus, 2005; Forsetlund et al., 2009). Multifaceted interventions, in which physicians, patients, and the community are selected as target groups, have been demonstrated to be most effective (Arnold \& Straus, 2005). Interventions aimed at patients and reminders to physicians have been viewed as the most promising methods (Yourman, Concato, \& Agostini, 2008).

The delivery of healthcare services in Turkey together with a shift toward prioritizing primary healthcare and family medicine practice in the country began within the last decade. In support of this process, various continuing medical education programs for family physician planning are on the agenda. In this study, a strong theoretical basis for physician education to improve irrational prescribing, one of the major problems faced by primary care physicians, was evaluated. The physicians were satisfied with the training, and they gave high scores for its content and quality. However, in the open-ended questions, they also noted that the training duration was insufficient, and they suggested that it should be repeated. There were no significant differences in the physicians' attitudes, subjective norms, or intentions following the intervention; however, there was a significant increase in the judgment "The decision to prescribe/ 
recommend medicine is entirely up to me," which could be considered the initial step in an attitude change in these physicians.

The burden of daily routines, inadequate time, and ineffective communication and coordination between healthcare practitioners, in addition to patients' self-treatment with OTC medications, were indicated as the main reasons for polypharmacy in previous studies (Thomsen, Thomsen, Winterstein, Søndergaard, Haugbølle, \& Melander, 2007). Most GPs do not examine half of the patients they see each day, they do not inform the patients about their diagnoses, and they do not mention non-drug treatments (Akici \& Oktay, 2007). Similar results were obtained in our study. When participating physicians were asked about the most important factor in OTC misuse, they stated that time was a problem. They also felt that they had insufficient knowledge, and they did not believe they could change patients' attitudes.

Some studies have indicated that GPs do not consider themselves sufficiently competent to terminate medications initiated by specialists (Carey et al., 2008; Conner \& Norman, 1995). Only one-third of physicians informed their patients about this subject at each interview. Similarly, after the intervention, the physicians' responses to questions evaluating their attitudes using real patient scenarios indicated a tendency in the study group to turn down the requests of patients and third parties but to prescribe drugs suggested by other doctors.

Although the results were not as expected as those from the literature, the intervention method that was used in this study was demonstrated to be efficient and useful because of its multilayer approach in the previous studies. In our opinion, the underlying causes of this situation were that the intervention took place only once and that the duration was short. In addition, this study's objectives did not include investigating other organizational and political factors, such as primary care physicians' intensive workloads or their feelings of having to force themselves to satisfy all patient expectations.

This study demonstrated that family physicians are aware of their own training needs. The training method was acceptable and satisfactory. However, to effectively modify physicians' behaviors, as proposed in the literature, the training should be longer and should be repeated regularly. 


\section{Acknowledgments}

The authors would like to thank Prof. Vahide Savc1, Prof. Levent Özuysal, and Prof. Sibel Gürün for their valuable help in planning the course lectures and their contributions to training. The authors would also like to thank the family physicians who took part in the study.

\section{References}

Ajzen, I. (2011). The theory of planned behaviour: Reactions and reflections. Psych Health, 26, 1113-1127.

Akici, A., \& Oktay, S. (2007). Rational pharmacotherapy and pharmacovigilance. Current Drug Safety, 2, 65-69.

Akici, A., Kalaça, S., Ugurlu, M. U., Karaalp, A., Cali, S., \& Oktay, S. (2004). Impact of a short postgraduate course in rational pharmacotherapy for general practitioners. British Journal of Clinical Pharmacology, 57, 310-321.

Arnold, S. R., \& Straus, S. E. (2005). Interventions to improve antibiotic prescribing practices in ambulatory care. Cochrane Database of Systematic Reviews, 4, CD003539.

Carey, I. M., De Wilde, S., Harris, T., Victor, C., Richards, N., Hilton, S. R., \& Cook, D. G. (2008). What factors predict potentially inappropriate primary care prescribing in older people? Analysis of UK primary care patient record database. Drugs Aging, 25, 693-706.

Conner, M., \& Norman, P. (1995). Predicting health behaviour. Buckingham, UK: Open University Press.

De Vries, T. P. G. M., Henning, R. H., Hogerzeil, H. V., \& Fresle, D. A. (1994). Guide to good prescribing. Geneva: WHO.

Forsetlund, L., Bjørndal, A., Rashidian, A., Jamtvedt, G., O’Brien, M. A., Wolf, F. ... Oxman, A. D. (2009). Continuing education meetings and workshops: Effects on professional practice and health care outcomes. Cochrane Database of Systematic Revierws, 2, CD003030.

Hrisos, S., Eccles, M. P., Francis, J. J., Dickinson, H. O., Kaner, E. F., Beyer, F., \& Johnston, M. (2009). Are there valid proxy measures of clinical behaviour? A systematic review. Implement Science, 4(37). doi:10.1186/1748-5908-4-37. 
Lionis, C., Petelos, E., Shea, S., Bagiartaki, G., Tsiligianni, I. G., Kamekis, A. ... Merkouris, B. (2014). Irrational prescribing of over-the-counter (OTC) medicines in general practice: Testing the feasibility of an educational intervention among physicians in five European countries. BMC Family Practice, 15, 1-15.

Otoom, S. A., \& Sequeira, R. P. (2006). Health care providers' perceptions of the problems and causes of irrational use of drugs in two Middle East countries. International Journal of Clinical Practice, 60, 565-570.

Thomsen, L. A., Winterstein, A. G., Søndergaard, B., Haugbølle, L. S., \& Melander, A. (2007). Systematic review of the incidence and characteristics of preventable adverse drug events in ambulatory care. Ann Pharmacother, 41, 1411-1426.

Tsiantou, V., Shea, S., Martinez, L., Agius, D., Basak, O., Farwsjö, T. ... Lionis, C. (2013). Eliciting general practitioners' salient beliefs towards prescribing: A qualitative study based on the theory of planned behaviour in Greece. Journal of Clinical Pharmacy and Therapeutics, 38, 109-114.

World Health Organization. (2012). Medicines: Rational use of medicines (Fact sheet no 338). Retrieved from http://www.who.int/mediacentre/factsheets/fs338/en/

Yourman, L., Concato, J., \& Agostini, J. V. (2008). Use of computer decision support interventions to improve medication prescribing in older adults: A systematic review. American Journal of Geriatric Pharmacotherapy, 6, 119-129. 